\title{
Repertório de habilidades sociais, problemas de comportamento, autoconceito e desempenho acadêmico de crianças no início da escolarização
}

\author{
Social skills repertory, behavioral problems, \\ self-concept and academic performance \\ among children in their early school years
}

Fabiana CIA

Elizabeth Joan BARHAM $^{2}$

\begin{abstract}
Resumo
Este estudo teve por objetivo relacionar o desenvolvimento socioemocional (repertório de habilidades sociais, problemas de comportamento, autoconceito) e o desempenho acadêmico de crianças. Participaram 97 pais e mães, 99 crianças (primeira e segunda séries) e 20 professoras. O repertório de habilidades sociais e os problemas de comportamento das crianças foram avaliados por ambos os pais, professoras e crianças por meio da Social Skills Rating Scale. O autoconceito das crianças foi autoavaliado com o Self-discription Questionnaire 1; o desempenho acadêmico foi avaliado pelas professoras com base na Social Skills Rating Scale e, posteriormente, junto às crianças, usando o Teste de Desempenho Escolar. Pôde-se verificar que o repertório de habilidades sociais, o autoconceito e o desempenho acadêmico das crianças estavam positivamente correlacionados entre si. Além disso, essas três variáveis estavam negativamente correlacionadas com os problemas de comportamento das crianças. Esses resultados são sugestivos da relação entre o desenvolvimento socioemocional e o desempenho acadêmico de crianças em fase de transição escolar e dos benefícios de programas para promover habilidades durante este período, em qualquer uma das áreas, com prováveis ganhos na segunda.
\end{abstract}

Unitermos: Autoconceito. Desempenho acadêmico. Habilidades sociais. Problemas de comportamento. Transição.

\begin{abstract}
This study aims to examine the relationships between children's socio-emotional development (social skills, internalizing and externalizing behavioral problems and self-concept) and their academic achievement. Study participants included 97 mothers and fathers, 99 children in grades one or two, and 20 teachers. The children's repertory of social skills and behavioral problems was evaluated by parents, teachers and children (Social Skills Rating Scale). The children's self-concept was assessed using self-evaluations (Self-description Questionnaire 1); the children's academic performance was evaluated by the teachers based on the Social Skills Rating Scale, and subsequently together with the children using the School Performance Test. Significant positive correlations were found among the children's repertory of social skills,
\end{abstract}

1 Universidade Federal de São Carlos, Programa de Pós-graduação em Educação Especial. R. Episcopal, 1575, Centro, 13560-905, São Carlos, SP, Brasil. Caixa Postal 676, 13565-905, São Carlos, SP, Brasil. Correspondência para/Correspondence to: F. CIA. E-mail: <abianacia@hotmail.com>.

2 Universidade Federal de São Carlos, Programa de Pós-Graduação em Psicologia, Departamento de Psicologia. São Carlos, SP, Brasil.

Apoio: Fundação de Amparo à Pesquisa do Estado de São Paulo. 
self-concept and academic achievement. In addition, these threevariables were negatively correlated with the children's behavioral problems. These results point to there being a relationship between socio-emotional development and academic performance among children at the school-entry transition stage and the probable benefits of skills programs for children during this period, in either area, with gains also likely in the other area.

Uniterms: Self-concept. Academic achievement. Social skills. Behavioral problems. Transition.

O termo habilidades sociais refere-se ao conjunto de classes e subclasses comportamentais que o indivíduo apresenta para atender às diversas demandas das situações interpessoais; já a competência social deve ser entendida como a capacidade de o indivíduo organizar pensamentos, sentimentos e comportamentos em um desempenho que atenda adequadamente às demandas do ambiente social, supondo os seguintes critérios de avaliação:"consecução dos objetivos, manutenção ou melhora da autoestima e da qualidade da relação, equilíbrio de ganhos e perdas entre os parceiros da interação, respeito e ampliação dos direitos humanos" (A. Del Prette \& Z.A.P. Del Prette, 2001, p.34).

As dificuldades interpessoais (envolvendo problemas de comportamento internalizantes e externalizantes) ocorrem, de modo geral, por causa de um repertório de habilidades sociais pobre, principalmente em termos de empatia, expressão de sentimentos e resolução de problemas. A competência do indivíduo em relação a estas habilidades depende de fatores cognitivos e emocionais, como baixa autoestima, baixo autoconceito, crenças e atribuições disfuncionais, impulsividade e temperamento difícil, entre outros. Os problemas de comportamento externalizantes (expressados predominantemente em relação a outras pessoas) são mais frequentes em transtornos que envolvem agressividade física ou verbal, comportamentos opositores ou desafiadores, condutas antissociais (mentir e roubar) e comportamentos de risco (como uso de substâncias psicoativas). Os problemas de comportamento internalizantes (expressados predominantemente em relação ao próprio indivíduo) são mais prontamente identificáveis em transtornos como depressão, isolamento social, ansiedade e fobia social (Z.A.P. Del Prette \& A. Del Prette, 2005; Gresham \& Elliott, 1990).

Nas diferentes fases de transição que existem no processo de desenvolvimento, como no caso de crian46 ças da primeira e segunda séries, é necessário aprender a lidar com novas demandas sociais. Assim, a competência social das crianças torna-se um fator importante para seu ajustamento social e sucesso no ambiente escolar. Segundo Marturano (2004), o ingresso no ensino fundamental constitui um ponto de transição importante na vida da criança porque inúmeras mudanças ocorrem simultaneamente, requerendo adaptações elaboradas. Isso ocorre porque não só os contextos físicos e sociais diferenciam-se dos conhecidos pela criança na fase pré-escolar, mas as expectativas do meio social tornam-se mais exigentes, a dependência é menos tolerada, as regras de convívio social ficam mais complexas e o suporte fica menos disponível. A exposição ao julgamento do outro instiga na criança a motivação para corresponder às expectativas, muitas vezes conflitantes, da família, da escola e do grupo de companheiros. Nas relações interpessoais, tem-se a exigência de negociar interações não apenas com as crianças da mesma idade, mas também com crianças mais velhas, o que pode aumentar o stress que a criança experimenta durante esta transição.

Várias pesquisas apontam que, quanto maior a frequência de problemas de comportamento apresentados pelas crianças, pior o repertório de habilidades sociais, o autoconceito e o desempenho acadêmico das mesmas (Cia, Pamplin \& Z.A.P. Del Prette, 2006; Chapman, Tunmer \& Prochnow, 2000; D'Avila-Bacarji, Marturano \& Elias, 2005; Z.A.P. Del Prette \& A. Del Prette, 2005; Dessen \& Szelbracikowski, 2004; Dunn, Cheng, O'Connor \& Bridges, 2004; Formiga, 2004; Hong \& Ho, 2005). A seguir, consideram-se alguns estudos descrevendo as relações entre dificuldades de aprendizagem e as avaliações destas crianças, envolvendo: a) habilidades sociais; b) autoconceito; e c) problemas de comportamento.

A maioria das crianças com dificuldades de aprendizagem é negativamente avaliada em sua competência social por colegas, professores e até mesmo por pais (Z.A.P. Del Prette \& A. Del Prette, 2005). Segundo esses autores, os professores apontam que são crianças 
mais agressivas, imaturas, menos orientadas para a tarefa, mais passivas e dependentes, menos consideradas pelos colegas em suas opiniões, com mais problemas de comportamento e, em situações não escolares, apresentam dificuldades de conversação, de juntar-se a um grupo de atividade, de desenvolver e manter amizade, de compartilhar brincadeiras e interagir com colegas, sendo geralmente referidas como inquietas briguentas, inibidas e sem iniciativa. Além disso, na avaliação dos pais, essas crianças apresentam impulsividade, baixo autocontrole, ansiedade, dispersão e déficits em habilidades verbais.

Ainda considerando a relação entre o repertório de habilidades sociais e o desempenho acadêmico, Miles eStepek (2006) realizaram um estudo longitudinal com 400 crianças de 4 a 6 anos (início do estudo), com o objetivo de verificar a associação entre o repertório de habilidades sociais (agressão e comportamento pró-social) e o desempenho acadêmico, em diferentes idades (primeira, terceira e quinta séries). Os resultados mostraram que as crianças com melhor desempenho acadêmico na primeira série apresentaram maior frequência de comportamentos pró-sociais e melhor desempenho acadêmico na terceira e quinta séries. As crianças com maior frequência de comportamentos agressivos na primeira série apresentaram maior frequência destes comportamentos nas séries seguintes e pior desempenho acadêmico. Esses autores concluíram que o desempenho acadêmico e o repertório de habilidades sociais estão positivamente correlacionados.

Resultados similares aparecem em estudos que examinam a relação entre desempenho acadêmico e autoconceito. Um exemplo da abrangência dos danos para o autoconceito, quando a criança apresenta dificuldades de aprendizagem, vem do estudo de Okano, Loureiro, Linhares e Marturano (2004). Essas pesquisadoras avaliaram o autoconceito de quarenta crianças da primeira à quarta séries do ensino fundamental. Os participantes estavam divididos em grupos de crianças com e sem dificuldades de aprendizagem. Os resultados mostraram que as crianças sem dificuldades de aprendizagem apresentaram autoconceito global e autoconceito em cinco das seis subcategorias (comportamental, status intelectual e acadêmico, ansiedade e popularidade) mais positivos do que as crianças com dificuldades de aprendizagem. Essas autoras concluíram que as crianças com dificuldades escolares percebem- -se com menor habilidade para aprender e com mais dificuldades comportamentais, no sentido de terem menor capacidade de se ajustar às demandas do meio, quando comparadas às crianças sem dificuldades de aprendizagem.

Deve-se ressaltar que as crianças com características interpessoais positivas têm maior probabilidade de uma trajetória desenvolvimental satisfatória. A ausência destas características é tida como fator de risco, podendo levar a criança a apresentar dificuldades de aprendizagem (Z.A.P. Del Prette \& A. Del Prette, 2005; Dunn et al., 2004; Ferreira \& Marturano 2002), problemas comportamentais ou emocionais (Bolsoni-Silva \& A. Del Prette, 2002; Marturano, 2004), entre outros desajustes psicossociais (Coley, Morris \& Hernandez, 2004; Oliveira et al., 2002).

Desta forma, crianças com problemas de comportamento e baixo desempenho escolar são consideradas em situação de risco, pois, no Brasil, um número cada vez maior de alunos, quando não são bem sucedidos na escola, são erroneamente rotulados e classificados como deficientes, e encaminhados para classes ou escolas especiais. Outra parte desses alunos engrossa as estatísticas sobre o número de pessoas com baixo nível de rendimento escolar e altos níveis de repetência e evasão, que constituem fracasso escolar. Todos esses problemas aparecem com uma frequência significativamente maior entre as crianças de camadas socioeconômicas menos favorecidas (Brasil, 2002; Hallahan \& Kauffaman, 2003).

Apesar da existência de diversos estudos apontando a relação entre o repertório de habilidades sociais, os problemas de comportamento, o autoconceito e o desempenho acadêmico das crianças, nota-se que os mesmos não trabalham com todas essas variáveis simultaneamente, principalmente com crianças em início de escolarização. Diante desses pressupostos e da necessidade de analisar a vulnerabilidade que pode estar envolvida em fases de transição, como no início da escolarização, e com o intuito de aprimorar os conhecimentos sobre as variáveis pessoais que podem funcionar como fatores de proteção ou risco para a criança e, com isso, ajudá-las no processo de desenvolvimento posterior, este estudo teve por objetivo verificar a relação entre o repertório de habilidades sociais, os problemas de comportamento, o autoconceito e o desempenho acadêmico de crianças iniciando as atividades escolares. 


\section{Método}

\section{Participantes}

Pais e mães: essa pesquisa contou com a participação de 97 pais e mães e seus filhos crianças da primeira e segunda séries do ensino fundamental. A média de idade dos pais era de 35 anos (variando entre 23 e 58 anos) e a média de idade das mães era de 32 anos (variando entre 20 e 55 anos). O número de filhos foi, em média, dois, e todos os participantes eram casados. Em relação à classe socioeconômica, 7,1\% das famílias eram de classe D, 50,5\% eram de classe C, 35,4\% eram de classe B2 e 7,1\% eram de classe B1 (Critério Brasil, 2006).

Crianças: foram participantes deste estudo 99 crianças (duas famílias tinham gêmeos), com idade média de oito anos (variando entre seis e nove anos). Destas crianças, 49 eram do sexo masculino e 50 do sexo feminino; 21,2\% estavam na primeira série e 78,8\% estavam na segunda série do ensino fundamental.

Professoras: participaram deste estudo vinte professoras, com média de idade de 40 anos (variando entre 25 e 59 anos). Seis delas lecionavam para a primeira série e 14 para a segunda série do ensino fundamental. Em média, estas professoras lecionavam há 14 anos, e apenas duas delas estavam cursando o terceiro grau (com formação em pedagogia); o restante tinha terceiro grau completo (15 professoras formadas em pedagogia, uma em letras, uma em história e outra em pedagogia eletras).

A coleta de dados ocorreu em duas escolas municipais e uma escola estadual localizadas em um município no interior do estado de São Paulo.

\section{Instrumentos}

- Pais e mães: Social Skills Rating System (SSRS) versão para pais. Este sistema avalia o repertório de habilidades sociais, os problemas de comportamento e a competência acadêmica de crianças (da pré-escola à sexta série). Foi elaborado por Gresham e Elliott (1990) e validado para o contexto brasileiro por Bandeira, Z.A.P. Del Prette, A. Del Prette e Magalhães (no prelo). Esta versão do SSRS foi aplicada para avaliar a percepção dos pais quanto ao repertório de habilidades sociais e à existência e intensidade de problemas de comportamento internalizantes e externalizantes nas crianças. É composta de duas escalas tipo Likert: a) 38 itens, em que os pais assinalam com que frequência (nunca, algumas vezes e muito frequente) a criança age da forma descrita em cada uma das situações de interação social; esses itens são distribuídos em seis fatores: cooperação, asserção positiva, iniciativa/desenvoltura social, asserção de enfrentamento, civilidade e autocontrole; e b) 17 itens, em que os pais assinalam com qual frequência (nunca, algumas vezes e muito frequente) a criança emite cada um dos comportamentos problemáticos (distribuídos em três fatores: hiperatividade, comportamentos problemáticos externalizantes e comportamentos problemáticos internalizantes).

- Crianças: Social Skills Rating System (SSRS) - Autoavaliação. Esta versão, elaborada por Gresham \& Elliott (1990) e validada para o contexto brasileiro por Bandeira et al. (no prelo), foi aplicada para as crianças se autoavaliarem quanto ao seu repertório de habilidades sociais. É composta de uma escala tipo Likert de 34 itens, distribuídos em seis fatores: responsabilidade, empatia, assertividade, autocontrole, civilidade e expressão de sentimento positivo, em que a criança assinala com que frequência (nunca, algumas vezes e muito frequente) age da forma descrita em cada uma das situações de interação social.

- Questionário para avaliação do autoconceito/ Self-description Questionnaire 1 (SDQ1). Para avaliar o autoconceito das crianças, foi utilizado o questionário Self-description Questionnaire 1 (SDQ1), elaborado por Marsh e Smith (1982), validado na Inglaterra e na Austrália, e que está sendo adaptado para o contexto brasileiro por Garcia e De Rose (2000). Este questionário é composto de 76 itens distribuídos em oito escalas (habilidades físicas, aparência física, relacionamento com os colegas, relacionamento com os pais, leitura, matemática, assuntos escolares em geral e autoconceito geral). Essas oito escalas são divididas em duas categorias: autoconceito não-acadêmico e autoconceito acadêmico. Para completar o questionário, as crianças respondem a uma série de afirmações, usando uma escala tipo Likert com pontuações variando entre 1 (sempre falso) e 5 (sempre verdade) a respeito de cada afirmação.

- Teste de Desempenho Escolar (TDE): para obter um índice do desempenho escolar das crianças, foi utilizado o Teste de Desempenho Escolar (TDE) (Stein, 1994), um instrumento com propriedades psicométricas 
adequadas (confiabilidade interna) que avalia as capacidades fundamentais para o desempenho escolar. Esse teste foi concebido para a avaliação de escolares de primeira a sexta séries do ensino fundamental e é composto de três subtestes: a) escrita, envolvendo a escrita do nome próprio e de 34 palavras isoladas, apresentadas sob a forma de ditado; b) aritmética, requerendo a solução oral de três problemas e cálculos de 35 operações aritméticas por escrito; e c) leitura, requerendo o conhecimento de setenta palavras isoladas do contexto.

- Professores: Social Skills Rating System (SSRS) versão para professores. Esta versão, elaborada por Gresham \& Elliott (1990) e validada para o contexto brasileiro por Bandeira et al. (no prelo), foi aplicada para avaliar a percepção das professoras quanto à adequação do repertório de habilidades sociais e à existência e intensidade de problemas de comportamento internalizantes e externalizantes das crianças, em contexto de sala de aula. É composta de duas escalas tipo Likert: a) 30 itens, em que a professora assinala com que frequência (nunca, algumas vezes e muito frequente) a criança age da forma descrita em cada uma das situações de interação social; esses itens são distribuídos em cinco fatores: responsabilidade/cooperação, asserção, autocontrole, autodefesa e cooperação com pares; b) 18 itens, em que a professora assinala com que frequência (nunca, algumas vezes e muito frequente) a criança emite cada um dos comportamentos problemáticos; esses itens são distribuídos em dois fatores: comportamentos problemáticos externalizantes e comportamentos problemáticos internalizantes; e c) nove itens abordando o desempenho do aluno em leitura e matemática, sua motivação geral, a participação dos seus pais, seu funcionamento intelectual e comportamento geral em classe, classificando o aluno em uma das seguintes categorias: entre os 10\% piores da sala, entre os 20\% piores da sala, entre os 40\% médios da sala, entre $20 \%$ bons da sala ou entre os $10 \%$ ótimos da sala.

\section{Procedimentos}

As professoras assinaram um Termo de Consentimento Livre e Esclarecido autorizando sua participação na pesquisa, e ambos os pais assinaram o mesmo termo para autorizar sua participação e a das crianças. Em seguida, foi agendado um horário para que os pais e as professoras preenchessem o SSRS (versão para pais e versão para professores, respectivamente). A pesquisadora sempre indicou o nome da criança, estudante da primeira ou segunda série do ensino fundamental, que o pai (no caso de ter mais filhos na mesma faixa etária) ou professora deveria avaliar.

Concomitantemente à coleta de dados com ambos os pais e as professoras, aplicaram-se os seguintes testes nas crianças: Self-description Questionnaire 1 (SDQ1) (aplicação coletiva, com tempo para aplicação de 30 minutos), Teste de Desempenho Escolar (TDE) (aplicação individual, com tempo para aplicação de 45 minutos) e Social Skills Rating System (SSRS), Autoavaliação (aplicação coletiva, com tempo para aplicação de 20 minutos). Essas avaliações foram realizadas em mais de um dia. Os grupos tinham até cinco alunos, para que as crianças se sentissem mais confiantes e menos ansiosas, e para que a coleta de dados ocorresse em um clima agradável e acolhedor. No caso dos instrumentos SDQ1 e SSRS, Autoavaliação, a pesquisadora auxiliou na leitura e explicação de cada item. A coleta de dados seguiu o mesmo procedimento nas três instituições de ensino.

Os dados obtidos por meio do SSRS - versão para pais, SSRS, Autoavaliação, SDQ1, TDE e SSRS, Versão para professores foram pontuados com base nos procedimentos indicados nos seus respectivos manuais. Nos subtestes do TDE de escrita, leitura e aritmética, foi dado um ponto para cada resposta correta. Para correlacionar as medidas do desenvolvimento socioemocional com os do desempenho acadêmico (segundo o TDE) das crianças, foi necessário combinar os escores das crianças da primeira e segunda séries do ensino fundamental no TDE. Sempre que é preciso combinar dados de dois grupos independentes, com distribuições normais, mas médias diferentes, pode-se subtrair ou somar um valor fixo a todos os escores de um dos grupos, para transpor a média para o mesmo valor do segundo grupo, sem afetar a forma da distribuição dos escores do primeiro grupo (Hays, 1981). Assim, optou-se por transformar os escores das crianças da primeira série para ter uma distribuição equivalente aos das crianças da segunda série. Para tanto, foram acrescentados cinco pontos aos escores de cada criança da primeira série em aritmética, oito pontos em escrita, quatro pontos em leitura e 17 pontos no escore total. 
As relações entre os indicadores do repertório social das crianças (habilidades sociais, comportamento internalizantes e externalizantes), do autoconceito e do desempenho acadêmico foram verificadas por meio do teste de correlação de Pearson $(p<0,05)$.

\section{Resultados}

\section{Desempenho acadêmico e socioemocional das crianças}

O repertório de habilidades sociais das crianças foi avaliado por ambos os pais, pelas próprias crianças e pelas professoras (Tabela 1). Considerando a opinião dos quatro informantes, na maioria dos fatores as crianças apresentaram um repertório de habilidade sociais médio, segundo a amostra de referência (Bandeira et al., no prelo), com exceção do fator 1 , responsabilidade, e do fator 6 , expressão de sentimentos positivos, em que as crianças se autoavaliaram com um repertório abaixo da média.

A Tabela 2 mostra os valores médios e os desvios-padrão da avaliação dos pais, das mães e das professoras quanto aos problemas de comportamento que observaram nas crianças.

Para os pais e as mães, as crianças apresentaram problemas de comportamento com uma frequência média, mas, segundo as professoras, as crianças estavam com problemas de comportamento acima da média, considerando a amostra de referência (Bandeira et al., no prelo).

Para os escores médios do SDQ1 (Tabela 3). Segundo a amostra de referência as crianças apresentaram, em média, um autoconceito satisfatório (Garcia \& De Rose, 2000), e o relacionamento com os pais e a leitura foram as subescalas em que as crianças apresentaram melhor autoconceito.

O desempenho acadêmico das crianças foi avaliado pelas professoras e com as crianças (Tabela 4).

Segundo a amostra de referência (Stein, 1994) para a segunda série do ensino fundamental, as crianças obtiveram uma pontuação média em aritmética, leitura e escrita no TDE. Segundo a avaliação das professoras, de modo geral, as crianças apresentaram uma pontuação média (Bandeira et al., no prelo).
Tabela 1. Frequência de comportamentos habilidosos apresentados pelas crianças, em cada fator do SRSS, na avaliação dos pais, mães, crianças e professoras. São Carlos (SP), 2006.

\begin{tabular}{|c|c|c|c|}
\hline Habilidades sociais & Média & $\begin{array}{l}\text { Desvio- } \\
\text { padrão }\end{array}$ & Encore médio \\
\hline \multicolumn{4}{|l|}{ Pais } \\
\hline F1-Cooperação & 11,5 & 4,98 & $7,13-14,99$ \\
\hline F2-Asserção positiva & 10,2 & 3,78 & $9,60-14,78$ \\
\hline $\begin{array}{l}\text { F3-Iniciativa/desenvoltura } \\
\text { social }\end{array}$ & 9,7 & 4,15 & $7,82-14,02$ \\
\hline $\begin{array}{l}\text { F4-Asserção de } \\
\text { enfrentamento }\end{array}$ & 9,9 & 3,98 & $8,59-14,35$ \\
\hline F5-Civilidade & 7,1 & 2,96 & $4,76-9,08$ \\
\hline F6-Autocontrole & 4,6 & 2,30 & $2,06-5,64$ \\
\hline Total & 42,4 & 15,2 & $35,08-53,36$ \\
\hline \multicolumn{4}{|l|}{ Mães } \\
\hline F1-Cooperação & 11,4 & 5,06 & $7,13-14,99$ \\
\hline F2-Asserção positiva & 10,2 & 3,78 & $9,60-14,78$ \\
\hline $\begin{array}{l}\text { F3-Iniciativa/desenvoltura } \\
\text { social }\end{array}$ & 9,4 & 4,19 & $7,82-14,02$ \\
\hline $\begin{array}{l}\text { F4-Asserção de } \\
\text { enfrentamento }\end{array}$ & 10,1 & 4,06 & $8,59-14,35$ \\
\hline F5-Civilidade & 7,1 & 2,98 & $4,76-9,08$ \\
\hline F6-Autocontrole & 4,7 & 2,19 & $2,06-5,64$ \\
\hline Total & 38,4 & 14,4 & $35,08-53,36$ \\
\hline \multicolumn{4}{|l|}{ Crianças } \\
\hline F1-Responsabilidade & 9,6 & 3,23 & $9,65-13,77$ \\
\hline F2-Empatia & 4,9 & 1,75 & $3,67-7,09$ \\
\hline F3-Assertividade & 8,9 & 3,39 & $6,87-12,19$ \\
\hline F4-Autocontrole & 5,3 & 1,91 & $4,49-7,57$ \\
\hline F5-Civilidade & 5,9 & 2,76 & $4,43-8,49$ \\
\hline $\begin{array}{l}\text { F6-Expressão de } \\
\text { sentimentos positivos }\end{array}$ & 4,6 & 2,36 & $5,25-8,11$ \\
\hline Total & 33,1 & 10,1 & $32,43-44,87$ \\
\hline \multicolumn{4}{|l|}{ Professoras } \\
\hline $\begin{array}{l}\text { F1-Responsabilidade/ } \\
\text { cooperação }\end{array}$ & 21,1 & 6,48 & $15,35-28,61$ \\
\hline F2-Asserção & 11,5 & 3,68 & $6,86-15,22$ \\
\hline F3-Autocontrole & 11,5 & 3,81 & $8,34-16,20$ \\
\hline F4-Autodefesa & 3,4 & 1,52 & $1,67-5,11$ \\
\hline F5-Cooperação com pares & 5,1 & 2,06 & $2,61-6,69$ \\
\hline Total & 39,7 & 11,2 & $28,73-51,83$ \\
\hline
\end{tabular}

\section{Relações entre os indicadores de desempenho acadêmico e desenvolvimento socioemocional das crianças}

O desempenho acadêmico, o autoconceito e o repertório de habilidades sociais das crianças estiveram positivamente correlacionados entre si. Em contrapartida, quanto maiores os problemas de comportamento apresentados pelas crianças, menor o desempenho 
Tabela 2. Problemas de comportamento observados nas crianças: avaliação dos pais, mães e professoras. São Carlos (SP), 2006.

\begin{tabular}{lrrr}
\hline & Média & $\begin{array}{l}\text { Desvio- } \\
\text { padrão }\end{array}$ & $\begin{array}{l}\text { Norma de } \\
\text { referência }\end{array}$ \\
\hline Avaliação dos pais & & & \\
HIP & 4,5 & 3,27 & $0,62-3,66$ \\
CPI & 2,5 & 2,04 & $2,52-6,26$ \\
CPE & 5,4 & 3,44 & $3,53-8,77$ \\
CPT & 12,5 & 7,7 & $8,04-19,18$ \\
Avaliação das mães & & & \\
HIP & 4,7 & 3,42 & $0,62-3,66$ \\
CPI & 2,7 & 2,17 & $2,52-6,26$ \\
CPE & 5,6 & 3,41 & $3,53-8,77$ \\
CPT & 13,0 & 7,72 & $8,04-19,18$ \\
Avaliação das professoras & & & \\
CPI & 3,9 & 3,25 & $0,00-3,24$ \\
CPE & 10,1 & 6,81 & $0,25-7,85$ \\
CPT & 13,4 & 8,42 & $0,87-8,97$ \\
\hline
\end{tabular}

HIP: hiperatividade; CPI: comportamentos problemáticos internalizantes; CPE: comportamentos problemáticos externalizantes; CPT: comportamentos problemáticos - total.

Tabela 3. Autoconceito das crianças. São Carlos (SP), 2006.

\begin{tabular}{|c|c|c|c|c|}
\hline \multirow{2}{*}{ Subescala do autoconceito } & \multirow{2}{*}{ Média } & \multirow{2}{*}{$\begin{array}{l}\text { Desvio- } \\
\text { padrão }\end{array}$} & \multicolumn{2}{|c|}{ Pontuação } \\
\hline & & & Mínima & Máxima \\
\hline Relacionamento com os pais & 31,5 & 7,57 & 11,0 & 40,0 \\
\hline Leitura & 30,9 & 8,33 & 9,0 & 40,0 \\
\hline Assuntos escolares em geral & 29,5 & 8,43 & 10,0 & 40,0 \\
\hline Matemática & 28,9 & 8,46 & 8,0 & 40,0 \\
\hline Relacionamento com os colegas & 28,9 & 7,93 & 9,0 & 40,0 \\
\hline Autoconceito geral & 28,8 & 8,52 & 8,0 & 40,0 \\
\hline Aparência física & 27,5 & 7,80 & 9,0 & 39,0 \\
\hline Habilidades físicas & 27,1 & 7,65 & 11,0 & 40,0 \\
\hline Autoconceito não acadêmico' ${ }^{1}$ & 28,8 & 7,30 & 10,50 & 39,5 \\
\hline Autoconceito acadêmico² & 30,2 & 8,95 & 9,33 & 40,0 \\
\hline Autoconceito total ${ }^{3}$ & 29,5 & 7,86 & 9,92 & 40,0 \\
\hline
\end{tabular}

A pontuação máxima para cada aspecto do autoconceito medida no SDQ 1 foi 40.

${ }^{1}$ Média: habilidades físicas, aparência física, relacionamento com os pais e com os colegas; ${ }^{2}$ Média: matemática, leitura e assuntos escolares em geral; ${ }^{3}$ Média de todas as habilidades. acadêmico, o autoconceito e o repertório de habilidades sociais. A única exceção foi a inexistência de correlação significativa entre os problemas de comportamento internalizantes das crianças, segundo as professoras, e o repertório de habilidades sociais das crianças, segundo mães e pais (Anexo).

\section{Discussão}

\section{Desempenho acadêmico e socioemocional das crianças}

Em geral, o desempenho acadêmico das crianças (avaliado pelo TDE e pelo SSRS, versão para professores), o autoconceito, os problemas de comportamento internalizantes e externalizantes (segundo pais e mães) e o repertório de habilidades sociais (segundo crianças, pais, mães e professores) estiveram na média, segundo a amostra de referência para cada instrumento e para cada tipo de avaliador. Partindo do pressuposto de que as crianças deste estudo estavam em fase de transição, e que um bom desempenho acadêmico e socioemocional significaria o cumprimento de tarefas desenvolvimentais importantes para essa faixa etária, o desempenho médio na faixa da maioria destas crianças indica que elas não estão sendo expostas a riscos apontados para o desenvolvimento infantil nesta fase (D'Avila-Bacarji et al., 2005; Marturano, 2004), embora exista uma margem considerável para procurar melhorias visando transformar estas influências em fatores de proteção. No entanto, deve-se ressaltar que as crianças se autoavaliaram com um repertório social um pouco abaixo da média para dois fatores no seu repertório de habilidades sociais.

Além dos problemas pontuais na área de habilidades sociais, as professoras apontaram índices de problemas de comportamento internalizantes e externalizantes acima da média, embora os pais não tenham apontado problemas desta natureza. Sem dúvida, a

Tabela 4. Desempenho acadêmico das crianças. São Carlos (SP), 2006).

\begin{tabular}{lccc}
\hline & Média & Desvio-padrão & Norma de referência (2a série) \\
\hline Subtestes - Teste de Desempenho Escolar & & 3,4 & 12,1 \\
Aritmética & 25,9 & 7,4 & $10-13$ \\
Escrita & 60,6 & $20-26$ & 21,7 \\
Leitura & 98,6 & $87-66$ & 8,78 \\
Escore total & 34,9 & $27,72-42,42$ \\
Social Skills Rating System - versão para professores & & \\
\hline
\end{tabular}


diferença entre as avaliações dos pais e das professoras reflete o fato de que as exigências comportamentais e a proximidade da relação adulto-criança são diferentes nos ambientes familiar e escolar. Embora as professoras acumulem experiência com um número elevado de crianças da mesma faixa etária, desenvolvendo alta capacidade para identificar comportamentos problemáticos na esfera escolar, a necessidade constante de lidar com um grupo grande de crianças poderia levar as professoras a ter pouca tolerância para comportamentos que desviam a atenção dos alunos. No entanto, tendo em vista que as normas de referência são específicas para cada grupo (mães, pais e professores), as avaliações elevadas de problemas de comportamento por parte das professoras é preocupante, porque problemas comportamentais apresentados pelas crianças no âmbito escolar podem levar a uma variedade de resultados negativos na adolescência, incluindo baixo rendimento acadêmico, aumento de ausência nas aulas, aumento do risco de envolvimento com drogas, pouco relacionamento com os pares, depressão, ansiedade, labilidade emocional e externalização de comportamentos problemas. Pesquisas mostram que, quando não corrigidos, esses problemas continuarão exercendo uma influência negativa na fase adulta (Bongers, Koot, Ende \& Verhulst, 2004; Coley et al., 2004; Ferreira \& Marturano, 2002; Oliveira et al., 2002).

Tendo em vista a importância da ajuda oferecida pelos pais e professores, especialmente nesta fase de escolarização, seria importante verificar a adequação dos estímulos oferecidos por eles para aprimorar o repertório social das crianças. Nesse sentido, seria necessário avaliar seu conhecimento da importância de suas intervenções nesta esfera e seu domínio de diferentes técnicas de ensino destas habilidades. Por exemplo, os pais podem ter dificuldades para estabelecer regras, tanto por meio de orientações e instruções, quanto por manejo de consequências (usando recompensas e punições) e oferecimento de modelos. Os professores, por sua vez, podem estar restringindo as oportunidades de interação em sala de aula, expressando aceitação diante de problemas crônicos de comportamento das crianças (como baixa participação, brigas ou grosserias entre os colegas) ou oferecendo modelos inadequados de relacionamento na interação que têm com os alunos (Z.A.P. Del Prette \& A. Del Prette, 2005), problemas que poderiam ser aprimorados com a realização de treinamentos com os professores e alunos. Intervenções com os educadores (pais e professores) seriam importantes, considerando que a baixa avaliação de pais e professores do repertório social de uma criança pode acarretar uma menor qualidade de interação com esta, resultando em um autoconceito menos positivo e, como consequência, um desempenho acadêmico rebaixado.

\section{Relações entre os indicadores de desempenho acadêmico e desenvolvimento socioemocional}

Encontraram-se correlações significativas entre o desempenho acadêmico (TDE e SSRS - versão para professores), o autoconceito, os problemas de comportamento (segundo pais e mães) e o repertório de habilidades sociais das crianças (segundo crianças, pais, mães e professoras). São diversas pesquisas que apontam para correlações entre essas variáveis (Z.A.P. Del Prette \& A. Del Prette, 2005; Diperna, 2006; Dunn et al., 2004; Hong \& Ho, 2005; Miles \& Stepek, 2006; Marturano, 2004; Morrison, Brown, D'Incau, O'Farrell \& Furlong, 2006; Okano et al., 2004). Possivelmente, estas correlações existem porque as crianças com melhor desenvolvimento socioemocional são mais confiantes, mais persistentes em suas atividades acadêmicas, têm menos medo de errar (e, por isso, não temem competições), relacionam-se melhor com outras pessoas (colegas, pais e professores) e se responsabilizam pelos seus fracassos e sucessos (Simões, 1997). Desta forma, as escolas poderiam pensar em maneiras de aumentar a efetividade das estratégias usadas nas salas de reforços ou na realização de atividades paralelas com as crianças com dificuldades de aprendizagem, à medida que costumam trabalhar com uma abordagem focada nas questões acadêmicas em si (como ocorre nas três instituições de ensino onde os dados foram coletados), sem atentar para a eficácia dessas estratégias para sanar os problemas socioemocionais das crianças, que tanto interferem no seu desempenho acadêmico.

Nesse sentido, Marturano (2004) evidenciou, em seus estudos, que as crianças que passaram por programas que ajudavam a superar tanto as dificuldades acadêmicas quanto as interpessoais apresentaram ganhos mais persistentes no progresso escolar e na redução das dificuldades emocionais, quando comparadas com crianças que tiveram apenas atendimento para superar as dificuldades acadêmicas. Assim, o treinamento de habilidades sociais no âmbito escolar, como parte das atividades curriculares, poderia ser implementado para melhorar a qualidade das habili- 
dades sociais das crianças, aproveitando melhor este fator de proteção para seu desenvolvimento.

Vale destacar a ausência de correlações significativas entre os problemas de comportamento internalizantes, segundo as professoras, e a frequência de comportamentos socialmente habilidosos por parte das crianças, segundo pais e mães. Uma criança que se retrai em grupos maiores (como em sala de aula) pode não ter este problema em um contexto de grupo menor (como no caso da família), ou pode receber maior atenção e apoio emocional dos pais do que do professor, ajudando-a a superar estes problemas no seu desempenho social na esfera familiar. Além disso, crianças com problemas de comportamento internalizantes (por exemplo, aquelas que não fazem perguntas) acabam recebendo menos atenção do que crianças com problemas de comportamento externalizantes (por exemplo, aquelas que gritam). Assim, as avaliações de problemas internalizantes podem ser menos acuradas do que as avaliações de comportamentos externalizantes, como refletido nas correlações sistematicamente menores envolvendo os comportamentos internalizantes, do que as envolvendo os comportamentos externalizantes. Desta forma, percebe-se que seria importante investigar as discrepâncias entre as avaliações de professores e pais com maior cuidado, porque podem ajudar a identificar as condições de um ambiente que são especialmente negativas para as crianças, bem como ajudar a descobrir condições que permitam que a criança melhore seu desempenho.

Juntando a ideia de minimizar discrepâncias importantes no desempenho da criança em diferentes ambientes (escolar e familiar), e lembrando que existe uma ampla margem para melhorias no desempenho das crianças que participaram deste estudo e outros citados neste trabalho, também seria importante pensar em iniciativas direcionadas aos pais. Considerando que a família é o principal ambiente no qual a criança se desenvolve e que há uma interdependência entre o ambiente familiar e o ambiente escolar - ou seja, os eventos que ocorrem em casa podem afetar o desempenho da criança na escola e vice-versa (Bronfenbrenner, 1996), seria interessante a escola oferecer encontros educativos para os pais sobre como maximizar o desenvolvimento dos seus filhos.

Além disso, a escola poderia realizar atividades com os professores junto aos pais e crianças no ambiente escolar, para que estes tenham maior conheci- mento sobre a escola e seus docentes, e para que os professores, por sua vez, passem a conhecer as características familiares das crianças para as quais lecionam. A escola também poderia oferecer oportunidades para os pais participarem das políticas e práticas escolares, podendo decidir em conjunto com os professores o que é melhor para os alunos. $O$ envolvimento dos pais na escola dos filhos é um importante suporte social, pois passam a ter maior informação sobre os comportamentos que podem favorecer o desempenho acadêmico dos filhos (como incentivá-los a estudarem diariamente e valorizar as suas conquistas acadêmicas), e também permite apoio mútuo entre os pais, que podem trocar experiências sobre a educação dos seus filhos, políticas e práticas educativas (Hill \& Taylor, 2004; Hill et al., 2004).

\section{Considerações Finais}

Este estudo confirma aspectos da literatura referentes à importância do desenvolvimento socioemocional para o desempenho acadêmico de crianças iniciando as atividades escolares. Fica evidente a importância de pesquisas com amostras ampliadas, considerando diferentes estratos sociais. Deve-se ressaltar que a natureza dos dados deste estudo foi correlacional, e que, portanto, conclusões sobre a direção causal não podem ser estabelecidas. Estudos longitudinais seriam indicados para monitorar a influência do desenvolvimento socioemocional sobre o desempenho acadêmico das crianças ao longo do desenvolvimento infantil.

Além disso, esses dados sugerem a relevância de investimentos para corrigir problemas de comportamento e melhorar as habilidades sociais e o autoconceito das crianças, tanto por meio de intervenção direta com as crianças quanto com os pais, mães e professores; por exemplo, aplicando o treinamento de habilidades sociais, resolução de problemas, modificação comportamental, entre outros.

\section{Referências}

Bandeira, M., Del Prette, Z. A. P., Del Prette, A., \& Magalhães, T. (no prelo). Escala de avaliação das habilidades sociais de estudantes do ensino fundamental, SSRS-BR: validação transcultural para o Brasil.

Bolsoni-Silva, A. T., \& Del Prette, A. (2002). O que os pais falam sobre suas habilidades sociais e de seus filhos? Argumento, 3 (7), 71-86. 
Bongers, H. L., Koot, H. M., Ende, J. V. D., \& Verhulst, F. C. (2004). Developmental trajectories of externalizing behaviors in childhood and adolescence. Child Development, 75 (5), 1523-1537.

Brasil. Ministério da Educação. (2002). Classe especial: ressignificando sua prática. Brasília:Secretaria de Educação Especial.

Bronfenbrenner, U. (1996). A ecologia do desenvolvimento humano: experimentos naturais e planejados. Porto Alegre: Artes Médicas.

Chapman, J. W., Tunmer, W. E., \& Prochnow, J. E. (2000). Early reading-related skills and performance, reading self-concept, and the development of academic self-concept: a longitudinal study. Journal of Educational Psychology, 92 (4), 703-708.

Cia, F., Pamplin, R. C. O., \& Del Prette, Z. A. P. (2006). Comunicação e participação pais-filhos: correlação com habilidades sociais e problemas de comportamento dos filhos. Paideia - Cadernos de Psicologia e Educação, 16 (35), 395-408.

Coley, R. L., Morris, J. E., \& Hernandez, D. (2004). Out-of-school care and problem behavior trajectories among low-income adolescents: Individual, family, and neighborhood characteristics as added risks. Child Development, 73 (3), 948-965.

Critério Brasil. (2006). Associação brasileira de empresas de pesquisa. Recuperado em fevereiro 5, 2007, disponível em http://www.abep.org

D’Avila-Bacarji, K. M. G., Marturano, E. M., \& Elias, L. C. S. (2005). Suporte parental: um estudo sobre crianças com queixas escolares. Psicologia em Estudo, 10 (1), 110-115.

Del Prette, A., \& Del Prette, Z. A. P. (2001). Psicologia das relações interpessoais: vivências para o trabalho em grupo. Petrópolis: Vozes.

Del Prette, Z. A. P., \& Del Prette A., (2005). Psicologia das habilidades sociais na infância: teoria e prática. Petrópolis: Vozes.

Dessen, M. A., \& Szelbracikowski, A. C. (2004). Crianças com problemas de comportamento exteriorizado e a dinâmica familiar. Interação em Psicologia, 8 (2), 171-180.

Diperna, J. C. (2006). Academic enablers and student achievement: implications for assessment and intervention services in the schools. Psychology in the Schools, 43 (1), 7-17.

Dunn, J., Cheng, H., O'Connor, T. G., \& Bridges, L. (2004). Children's perspectives on their relationships with their nonresident fathers: influences, outcomes and implications. Journal of Child Psychology and Psychiatry, 45 (3), 553-566.

Ferreira, M. C. T., \& Marturano, E. M. (2002). Ambiente familiar e os problemas do comportamento apresentados por crianças com baixo desempenho escolar. Psicologia: Reflexão e Crítica, 15 (1), 35-44.

Formiga, N. S. (2004). O tipo de orientação cultural e sua influência sobre os indicadores do rendimento escolar. Psicologia: Teoria e Prática, 6 (1), 13-29.

Garcia, S. C., \& De Rose, T. M. S. (2000). Autoconceito e desempenho escolar. Monografia de conclusão do curso de bacharelado em psicologia não-publicada, Universidade Federal de São Carlos.

Gresham, F. M., \& Elliott, S. N. (1990). Social skills rating system. Circle Pines, MN: American Guidance Service.

Hallahan, D. P., \& Kauffaman, J. M. (2003). Exceptionality and Special Education. In D. P. Hallahan \& J. M. Kauffaman (Orgs.), Exceptional learners: introduction to special education (pp.3-37). Boston: Allyn \& Bacon.

Hays, W. L. (1981). Statistics. Canada: Holt Reinhart \&Winston.

Hill, N. E., Castellino, D. R., Lansford, J. E., Nowlin, P., Dodge, K. A., Bates, J. E., et al. (2004). Parent academic involvement as related to school behavior, achievement and aspirations: demographic variations across adolescence. Child Development, 75 (5), 1491-1509.

Hill, N. E., \& Taylor, L. C. (2004). Parental school involvement and children's academic achievement. Current Directions in Psychological Science, 13 (4), 161-164.

Hong, S., \& Ho, H. (2005). Direct and indirect longitudinal effects of parental involvement on student achievement: second-orde latent growth modeling across ethnic groups. Journal of Educational Psychology, 97 (1), 32-42.

Marsh, H. W., \& Smith, I. D. (1982). Multitrait-multimethod analyses of two self-concept instruments. Journal of Educational Psychology, 74, 430-440.

Marturano, E. M. (2004). Fatores de risco e proteção no desenvolvimento sócio-emocional de crianças com dificuldades de aprendizagem. In E. G. Mendes, M. A. Almeida \& L. C. A. Williams (Orgs.), Avanços recentes em educação especial (pp.159-165). São Carlos: EDUFSCar.

Miles, S. B., \& Stepek, D. (2006). Contemporaneous and longitudinal associations between social behavior and literacy achievement in a sample of low-income elementary school children. Child Development, 77 (1), 103-117.

Morrison, G. M., Brown, M., D'Incau, B., O'Farrell, S. L., \& Furlong, M. J. (2006). Understanding resilience in educational trajectories: implications for protective possibilities. Psychology in the Schools, 43 (1), 19-31.

Okano, C. B., Loureiro, S. R., Linhares, M. B. M., \& Marturano, E. M. (2004). Crianças com dificuldades escolares atendidas em programa de suporte psicopedagógico na escola: avaliação do autoconceito. Psicologia:Reflexão e Crítica, 17 (1), 121-128.

Oliveira, E. A., Marin, A. H., Pires, F. B., Frizzo, G. B., Ravanello, T., \& Rossato, C. (2002). Estilos parentais autoritário e democrático-recíproco intergeracionais, conflito conjugal e comportamento de externalização e internalização. Psicologia: Reflexão e Crítica, 15 (1), 1-11.

Simões, M. F. J. (1997). Autoconceito e desenvolvimento pessoal em contexto escolar. Revista Portuguesa de Pedagogia, 31, 195-210.

Stein, L. M. (1994). Teste de desempenho escolar. São Paulo: Casa do Psicólogo.

Recebido em: 21/5/2007

Versão final reapresentada em: 16/7/2007

Aprovado em: 10/9/2007 


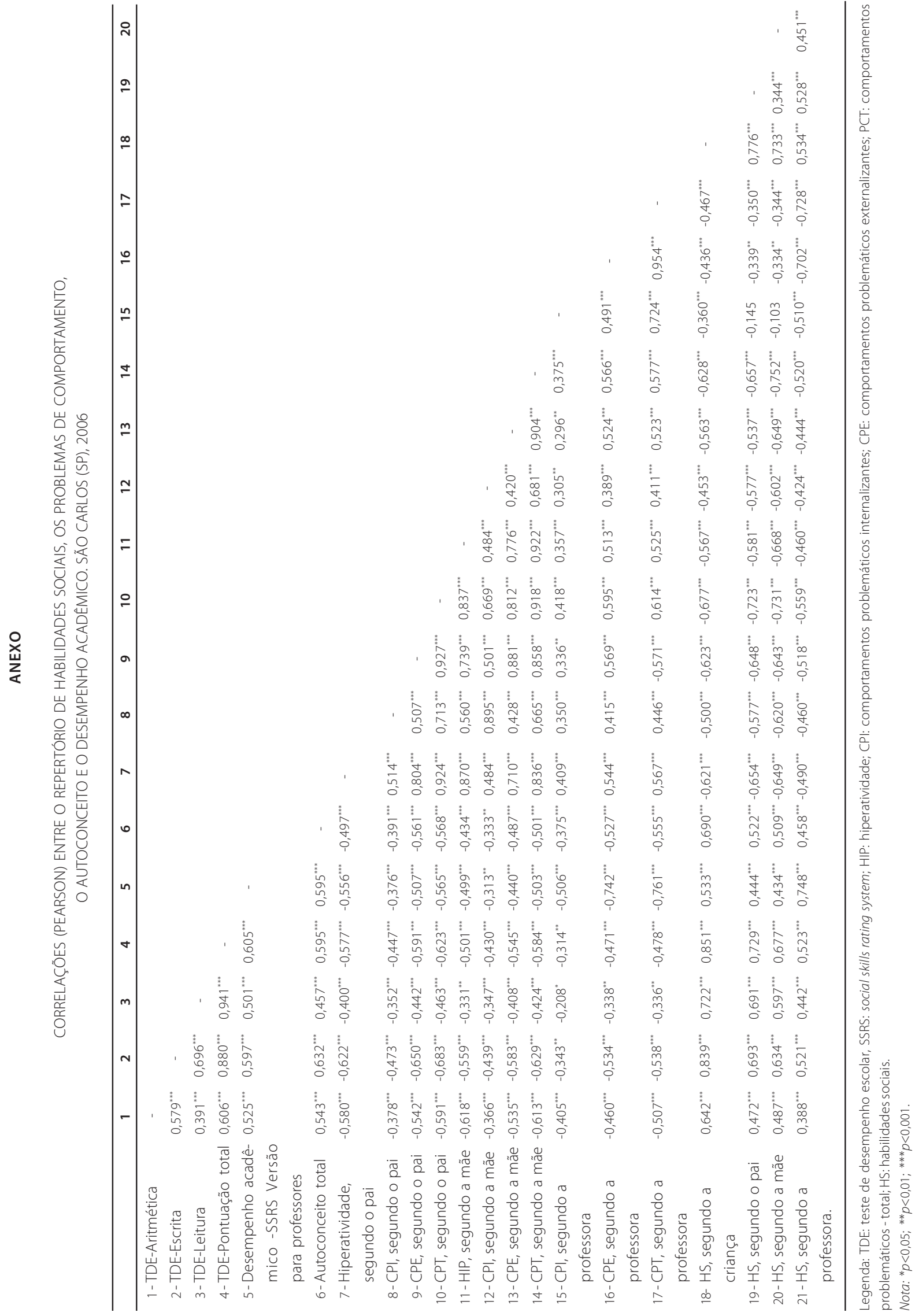

